\title{
段付棒に作用する衝撃力の測定理論*
}

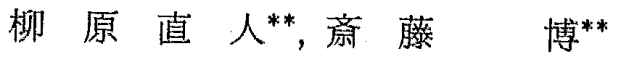

\section{A Measuring Theory of Impact Force Acting on a Bar with Two Different Diameters}

\author{
by Naoto YANAGIHARA and Hiroshi SAITO
}

\begin{abstract}
The true value of impact force, in high speed deformation tests of metals, is commonly measured by the use of the Hopkinson-bar method. But, a defect of this method is the restriction of measurable time because of the length of the bar. One of the authors suggested constructing a measuring theory for impact force acting on a bar with uniform cross sectional area, based on the theory of the propagation of longitudinal elastic stress waves. From the stresses detected at two points on the bar, two stress waves travelling in opposite directions along the bar axis are separated, and the impact force is estimated, without the restriction of the measuring time. This paper presents a new theory for measuring the impact force which occurs on a bar having two different diameters. The results of the experiments clearly confirm the correctness and usefulness of this theory.
\end{abstract}

Key Words : Shock, Measurement, One Dimensional Elastic Stress Wave, Different Cross Sectional Area, Use of Micro Computer

\section{1. 緒言}

高速変形試験などにおいて材料に作用する衝撃力を 正確に測定する場合には, 分割ホプキンソン圧縮棒法 (SHPB 法)が多く用いられている.しかし，この方法 は棒の長さによって測定時間が制約されるため, 測定 時間が長くなったり, 試験装置の都合上長い棒を使用 できない場合などには，応力波の反射の影響によって 測定できなくなる，そのため，最近では压電素子を衝 撃面に接着して測定する方法も検討されている。

著者らは，衝撃力を受ける丸棒において，衝撃力を 受ける断面から少し離れた 2 箇所にひずみゲージを接 着し,この 2 箸所で测定した応力の值から, 測定時間 の制約を受けずに衝撃力を求める理論(1) と衝撃面の速 度および変位量を求める理論を導き，その理論に基づ いた Yanagihara-bar 法の測定システムを完成させ た ${ }^{(2)(3)}$.これにより，短い棒を使っても丸棒の先端に 加わる衝撃力, 速度および変位量が時間の制約を受け ずに測定できるようになった。しかし，これまでの理 論では, 衝撃力の作用する部分と,ひずみゲージで応

\footnotetext{
* 昭和 60 年 11 月 20 日 関西支部第 245 回講演会において講 演, 原稿受付 昭和 60 年 3 月 7 日.

** 正員, 玉川大学工学部(画194 町田市玉川学園 6-1-1).
}

力を測定する部分とが，連続した同一の断面積を有す る棒でなければ適用できなかった。

本研究では，先の理諭に棒の断面積が異なる境界に おける応力波の透過と反射の影響を加えることによ り，衝撃力が作用する部分と，ひずみゲージで応力を 測定する部分の断面積が異なる段付棒においても適用 できる理論を導いている. そして，実験によって理諭 が有効であることを確認している．また，SHPB 法等 において，加圧棒の直径に対して試料の直径を減少さ せた場合に生ずる測定誤差の増加率を示している。

\section{2. 分離された応力波の理論(1)}

図 1 に示すように, 同一材料で断面積一様な丸棒の 任意の点に $\mathrm{a}$ 点と $\mathrm{b}$ 点を考光, その両者の間隔を $l_{1}$ とする。この丸棒内を応力波が伝ぱしているとき, 時 刻 $T$ に 点を通過している左右からの応力波の值を $\sigma_{L_{a}}(T), \sigma_{R_{a}}(T)$ とする.

この時の $\mathrm{a}$ 点と $\mathrm{b}$ 点の応力 $\sigma_{a}(T), \sigma_{b}(T)$ は, 応力 波が $\mathrm{a}$ 点から b 点まで伝ぱするのに必要な時間を $t_{1}$ とすると，それぞれ，次式によって表される。

$$
\begin{array}{r}
\sigma_{a}(T)=\sigma_{L a}(T)+\sigma_{R a}(T) \cdots \cdots \ldots \ldots \ldots \ldots \\
\sigma_{b}(T)=\sigma_{L a}\left(T-t_{1}\right)+\sigma_{R a}\left(T+t_{1}\right) \cdots \cdots \cdots \\
\text { 式(1)と, 時間をずらした式 }(2) \text { より, 次式 }
\end{array}
$$


$\sigma_{L a}(T)=\sigma_{a}(T)-\sigma_{b}\left(T-t_{1}\right)+\sigma_{L a}\left(T-2 t_{1}\right)$

が求められる，この式 $(3)$ を $2 t_{1}$ 時間ずつずらした式 を次々に代入して整理し，時間をずらして移項した式 （2）に代入することにより，左右方向からの応力波の 值は, 次式のように求まる.

$$
\begin{gathered}
\sigma_{L a}(T)=\sum_{n=0}^{k} \sigma_{a}\left(T-2 n t_{1}\right)-\sum_{n=0}^{k} \sigma_{b}\left(T-t_{1}-2 n t_{1}\right) \\
+\sigma_{L a}\left(T-2\{K+1\} t_{1}\right) \quad \cdots \cdots \cdots \cdots \cdots \cdots \cdots(4) \\
\sigma_{R a}(T)=\sum_{n=0}^{k} \sigma_{b}\left(T-t_{1}-2 n t_{1}\right)-\sum_{n=1}^{k} \sigma_{a}\left(T-2 n t_{1}\right) \\
-\sigma_{L a}\left(T-2\{K+1\} t_{1}\right) \quad \cdots \cdots \cdots \cdots \cdots \cdots \cdots(5)
\end{gathered}
$$

\section{3. 衝撃応力の測定理論}

時刻 $T$ において, 図 2 に示される段付棒内のd点 を通過している左右からの応力波を $\sigma_{L d}(T), \sigma_{R d}(T)$, 段付部の $\mathrm{c}$ 点から右側に発進する応力波を $\sigma_{l c}(T), \mathrm{c}$ 点に右側から入射してくる応力波を $\sigma_{R_{\mathrm{c}}}(T)$ とする.

また， $\mathrm{a}$ 点执よび $\mathrm{d}$ 点の方向から進行する応力波が $\mathrm{c}$ 点を通過するときの反射率 $\alpha_{1}, \alpha_{2}$ および透過率 $\beta_{1}$, $\beta_{2}$ は, $\mathrm{c}$ 点の右側と左側の断面積を $A_{1}, A_{2}$ とすると, 次式のように表される(4).

$$
\begin{aligned}
\alpha_{1} & =\frac{A_{2}-A_{1}}{A_{1}+A_{2}} \\
\alpha_{2} & =\frac{A_{1}-A_{2}}{A_{1}+A_{2}} \\
\beta_{1} & =\frac{2 A_{1}}{A_{1}+A_{2}} \\
\beta_{2} & =\frac{2 A_{2}}{A_{1}+A_{2}}
\end{aligned}
$$

応力波が $\mathrm{d}$ 点から $\mathrm{c}$ 点までの距離 $l_{3}$ を進行するの に必要な時間を $t_{3}$ とすると, 時刻 $T$ に点から右側 に発進する応力波 $\sigma_{L c}(T)$ は，その時にc 点に右側か ら入射した応力波の反射波と, $t_{3}$ 時間前にd 点を通過 してきた応力波の透過波との和であり，次式のように 表される.

$$
\sigma_{L c}(T)=\sigma_{R c}(T) \cdot \alpha_{1}+\sigma_{L d}\left(T-t_{3}\right) \cdot \beta_{2}
$$
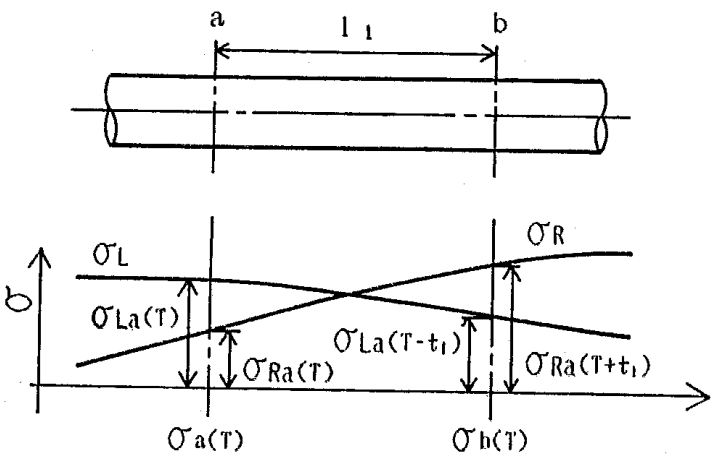

図 1 弾性丸棒内の忘力波伝ばモデル
また，時刻 $T に \mathrm{~d}$ 点を通過する右側からの応力波 $\sigma_{R d}(T)$ は，時刻 $T-t_{3} に c$ 点に右側から入射してき た応力波の透過波と，時刻 $T-2 t_{3}$ にd点を左側から 通過していった応力波によってc点で発生した反射波 との和であり, 次式のように表される.

$$
\sigma_{R d}(T)=\sigma_{R c}\left(T-t_{3}\right) \cdot \beta_{1}+\sigma_{L d}\left(T-2 t_{3}\right) \cdot \alpha_{2}
$$

式(10)を $t_{3}$ 時間だけずらして移行し, 式(11)に代入 して整理すると,

$$
\begin{gathered}
\sigma_{R d}(T)=\frac{1}{\beta_{2}}\left\{\sigma_{R c}\left(T-t_{3}\right) \cdot\left(\beta_{1} \cdot \beta_{2}-\alpha_{1} \cdot \alpha_{2}\right)\right. \\
\left.+\sigma_{L c}\left(T-t_{3}\right) \cdot \alpha_{2}\right\} \quad \ldots \ldots \ldots \ldots \ldots \ldots \ldots \ldots \ldots \ldots \ldots \ldots \ldots \ldots \ldots \ldots
\end{gathered}
$$

となる.ここで $\beta_{1} \cdot \beta_{2}-\alpha_{1} \cdot \alpha_{2}=1$ より, 式(12)は次式 のようになる.

$$
\sigma_{R d}(T)=\frac{1}{\beta_{2}}\left\{\sigma_{R c}\left(T-t_{3}\right)+\sigma_{L c}\left(T-t_{3}\right) \cdot \alpha_{2}\right\}
$$

次に，式(10)を $t_{3}$ 時間遅らせて移項することにより， 次式が求まる。

$$
\sigma_{L d}(T)=\frac{1}{\beta_{2}}\left\{\sigma_{L c}\left(T+t_{3}\right)-\sigma_{R c}\left(T+t_{3}\right) \cdot \alpha_{1}\right\}
$$

時刻 $T$ におけるd点の応力は，その時にd点を通過 している左右からの応力波の和として表され、これに $\alpha_{2}=-\alpha_{1}$ の条件を加えることにより

$$
\begin{aligned}
& \sigma_{d}(T)=\sigma_{L d}(T)+\sigma_{R d}(T) \\
& \quad=\frac{1}{\beta_{2}}\left\{\sigma_{L c}\left(T+t_{3}\right)+\sigma_{R c}\left(T-t_{3}\right)\right. \\
& \left.+\left[\sigma_{R c}\left(T+t_{3}\right)+\sigma_{L c}\left(T-t_{3}\right)\right] \cdot \alpha_{2}\right\}
\end{aligned}
$$

となる.いま, $\mathrm{c}$ 点から $\mathrm{a}$ 点までの距離 $l_{2}$ が $l_{3}$ と等し い場合には $t_{2}=t_{3}$ となり，これらの応力波を a 点を通 過する応力波で表すと次式のようになる。

$$
\begin{gathered}
\sigma_{d}(T)=\frac{1}{\beta_{2}}\left\{\sigma_{L a}\left(T+2 t_{3}\right)+\sigma_{R a}\left(T-2 t_{3}\right)\right. \\
\left.\quad+\left[\sigma_{R a}(T)+\sigma_{L a}(T)\right] \cdot \alpha_{2}\right\} \\
\ldots \ldots \ldots \ldots \ldots \ldots \ldots \ldots
\end{gathered}
$$

ここで, $\mathrm{a}$ 点から $\mathrm{b}$ 点までの距離 $l_{1}$ が $l_{3}$ と等しい
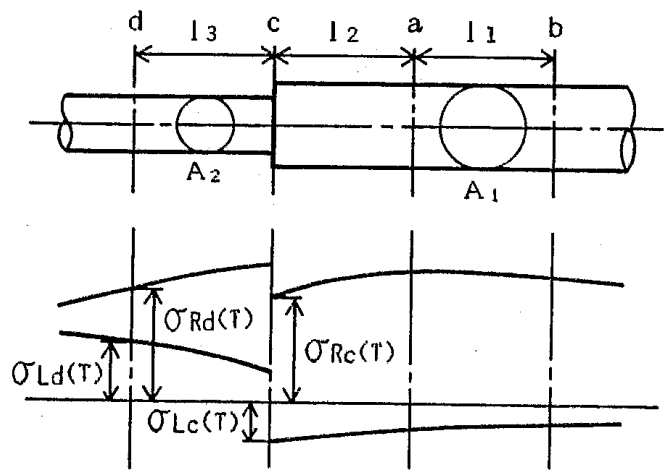

図 2 段付丸棒内の応力波モデ 
場合には $t_{3}=t_{1}$ となり，この式に式(4)，(5)の時間 をずらし，代入して整理し， $1+\alpha_{2}=\beta_{1}$ の条件を加光 ると，次式が求まる。

$$
\begin{gathered}
\sigma_{d}(T)=\frac{1}{\beta_{2}}\left\{\sigma_{a}\left(T+2 t_{1}\right)-\sigma_{b}\left(T+t_{1}\right)+\sigma_{a}(T) \cdot \beta_{1}\right. \\
\left.-\sigma_{b}\left(T-t_{1}\right)+\sigma_{a}\left(T-2 t_{1}\right)\right\} \cdots \cdots \cdots \cdots \cdots(17)
\end{gathered}
$$

上式に扔いて，丸棒の両断面積が等しい場合に扔い ては, $\beta_{2}=\beta_{1}=1$ となる.

また， $\mathrm{d}$ 点から $\mathrm{c}$ 点までの距離 $l_{3}$ を $l_{1}$ と等しくし， $\mathrm{c}$ 点から $\mathrm{a}$ 点までの距離 $l_{2}$ を $l_{1}$ の 2 倍とした場合に は, $t_{3}=t_{1}, t_{2}=2 t_{1}$ となり, 同様に整理すると次式が 求まる。

$$
\begin{aligned}
& \sigma_{d}(T)=\frac{1}{\beta_{2}}\left\{\sigma_{a}\left(T+3 t_{1}\right)-\sigma_{b}\left(T+2 t_{1}\right)\right. \\
& \quad+\left[\sigma_{a}\left(T+t_{1}\right)-\sigma_{b}(T)+\sigma_{a}\left(T-t_{1}\right)\right] \cdot \beta_{1} \\
& \left.\quad-\sigma_{b}\left(T-2 t_{1}\right)+\sigma_{a}\left(T-3 t_{1}\right)\right\} \cdots \cdots \cdots \cdots \cdots \cdots
\end{aligned}
$$

以降, $l_{3}=l_{1}$ とし, $k$ を 1 より大きい整数として, $l_{2}=$ $k l_{1}$ とした場合には， d点の応力は次式によって表す ことができる.

$$
\begin{aligned}
& \sigma_{d}(T)=\frac{1}{\beta_{2}}\left\{\sigma_{a}\left(T+[k+1] t_{1}\right)-\sigma_{b}\left(T+k t_{1}\right)\right. \\
& \quad+\left[\sum_{n=0}^{k-1} \sigma_{a}\left(T+[k-1-2 n] t_{1}\right)\right. \\
& \left.\quad-\sum_{n=1}^{k-1} \sigma_{b}\left(T+[k-2 n] t_{1}\right)\right] \cdot \beta_{1} \\
& \left.-\sigma_{b}\left(T-k t_{1}\right)+\sigma_{a}\left(T-[k+1] t_{1}\right)\right\} \quad \cdots \cdots(19)
\end{aligned}
$$

次に, 断面積の異なる部分の長さ $l_{3}$ を応力測定点 $\mathrm{a}, \mathrm{b}$ の間隔 $l_{1}$ の 2 倍とし, また, $l_{2}$ を $l_{1}$ と等しくし た場合を考える.このとき， $t_{3}=2 t_{1}, t_{2}=t_{1}$ となるた め,まず式(15)に $t_{3}=2 t_{1}$ を代入すると次式のように なる。

$$
\begin{gathered}
\sigma_{d}(T)=\frac{1}{\beta_{2}}\left\{\sigma_{L c}\left(T+2 t_{1}\right)+\sigma_{R_{c}}\left(T-2 t_{1}\right)\right. \\
\left.+\left[\sigma_{R c}\left(T+2 t_{1}\right)+\sigma_{L c}\left(T-2 t_{1}\right)\right] \cdot \alpha_{2}\right\} \cdots
\end{gathered}
$$

この式の右辺の応力波を $\mathrm{a}$ 点を通過する応力波で表 すと, 次式のようになる.

$$
\begin{aligned}
& \sigma_{d}(T)=\frac{1}{\beta_{2}}\left\{\sigma_{L a}\left(T+3 t_{1}\right)+\sigma_{R a}\left(T-3 t_{1}\right)\right. \\
& \left.\quad+\left[\sigma_{R a}\left(T+t_{1}\right)+\sigma_{L a}\left(T-t_{1}\right)\right] \cdot \alpha_{2}\right\} \cdots \cdots \cdots
\end{aligned}
$$

この式に, 式(4)，(5)の時間をずらして代入し，1 $+\alpha_{1}=\beta_{1}$ として整理すると次式が求まる。

$$
\begin{aligned}
& \sigma_{d}(T)=\frac{1}{\beta_{2}}\left\{\sigma_{a}\left(T+3 t_{1}\right)-\sigma_{b}\left(T+2 t_{1}\right)\right. \\
& +\sigma_{a}\left(T+t_{1}\right)-\sigma_{b}(T) \cdot \beta_{1}+\sigma_{a}\left(T-t_{1}\right) \\
& \left.-\sigma_{b}\left(T-2 t_{1}\right)+\sigma_{a}\left(T-3 t_{1}\right)\right\}
\end{aligned}
$$

$k$ を 2 より大きい整数として, $l_{3}$ を $l_{1}$ の $k$ 倍とし, $l_{2}$ と $l_{1}$ を等しくした場合には， $t_{3}=k t_{1}, t_{2}=t_{1}$ となり，
同様に整理することにょり次の式が求まる。

$$
\begin{aligned}
& \sigma_{d}(T)=\frac{1}{\beta_{2}}\left\{\sigma_{a}\left(T+[k+1] t_{1}\right)-\sigma_{b}\left(T+k t_{1}\right)\right. \\
& +\sigma_{a}\left(T+[k-1] t_{1}\right) \\
& +\left[\sum_{n=1}^{k-2} \sigma_{a}\left(T+[k-1-2 n] t_{1}\right)\right. \\
& \left.\quad-\sum_{n=1}^{k-1} \sigma_{b}\left(T+[k-2 n] t_{1}\right)\right] \cdot \beta_{1} \\
& \quad+\sigma_{a}\left(T-[k-1] t_{1}\right)-\sigma_{b}\left(T-k t_{1}\right) \\
& \left.\quad+\sigma_{a}\left(T-[k+1] t_{1}\right)\right\} \cdots \cdots \cdots \cdots \cdots \cdots \cdots \cdots \cdots \cdots \cdots \cdots \cdots \cdots \cdots \cdots \cdots
\end{aligned}
$$

このように, $\mathrm{d}$ 点の灾力は, 測定点までの距離が增 加すると演算回数は多くなるが, 衝撃が加わる部分と 応力を測定する部分の断面積が異なる場合においても 2 箇所の測定応力から求めることができる。また，前 報(1)で示したように, これらの式は， d 点が棒の端面 である場合にも適用できる。

\section{4. 衝撃実験による理論の確認}

上記の理論を確かめるため, 次のような実験を行っ た。実験装置は，図 3 のブロック線図に示すようなも ので，測定棒と衝撃棒は鋳鉄製のガイドと空圧式の加 速装置により同軸上に設置されている. 衝揧棒は, 直 径 $25 \mathrm{~mm}$, 長さ $400 \mathrm{~mm}$ の鋼製の丸棒である. 湘定棒 は長さ $270 \mathrm{~mm}$ の工具鋼製の丸棒で, 測定部の直径 $25 \mathrm{~mm}$, 先端は図 4 のように長さ $30,6 \mathrm{~mm}$ だけ直径 を $40 \mathrm{~mm}$ から $10 \mathrm{~mm}$ までの間で変化させ, その段付 部から $30,6 \mathrm{~mm}$ 間隔で a ダージと b ゲージが接着さ れている. ゲージはゲージ長 $2 \mathrm{~mm}$ の P 形と N 形の 半導体ゲージで，それぞれ軸対称に 2 枚ずつ接着され ており 4 ゲージ法で測定される.ゲージはブリッジボ ックスに接続され，その出力波形は周波数帯域 150 $\mathrm{kHz}$ のデジタルオシロスコープに送られ, $1 \mu \mathrm{s}$ 間隔 でサンプリングされて記憶される。記憶された応力波 形はマイクロコンピュータへRS-232C 方式, 2400 ボ 一で転送され，理論式に従って計算されてプリンタで 記録される，実験におけるブリッジ回路からの出力電 圧は, 測定棒の応力 $10 \mathrm{MPa}$ 当たり $14 \mathrm{mV}$ である.

図 5 の上方は, 先端部の直径比 $d / D$ が 0.8 の測定

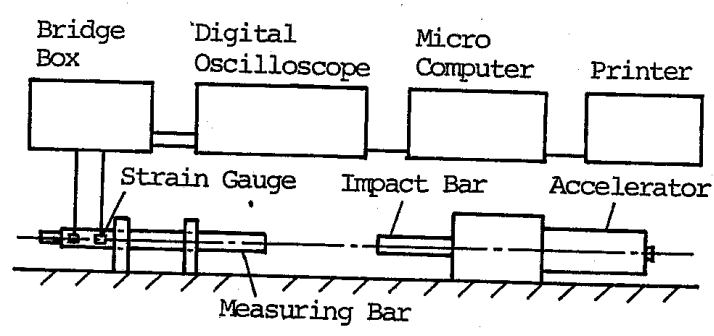

図 3 衝撃実験装置のブロック線図 
棒の後方から $4.0 \mathrm{~m} / \mathrm{s}$ の速度で衝撃棒を衝突させた 時に $\mathrm{a}$ 点と $\mathrm{b}$ 点で実測された応力波形である。その下 が，その応力から計算された測定棒先端の応力であ る.実験では, 測定棒の先端は自由端となっているの で, 応力は零となるのが理想であるが, 計算された応 力はわずかに変動しており， $\mathrm{a}$ 点と $\mathrm{b}$ 点の応力の変動 が大きな所で誤差も大きくなっている，また図 5 の下 方の図は， $d / D$ が 0.7 と 0.6 の時に計算された先端の 応力であり， $d / D$ の減少に従って誤差も増加してい る.

$\mathrm{a}$ 点と $\mathrm{b}$ 点の応力から, 断面積が変化する段付部に 発生している衝撃力 $F_{c}(T)$ が，次式によって計算て きる(1).

$$
F_{c}(T)=\left\{\sigma_{a}\left(T+t_{1}\right)-\sigma_{b}(T)+\sigma_{a}\left(T-t_{1}\right)\right\} \cdot A_{1}
$$

この段付部に扔いては, 直径 $D$ の丸棒の先端が直 径 $d$ の面積で衝撃力を受けているのと同一である。そ こで，この測定法の精度を調べるため，便宜的に，こ の段付部で発生した衝撃力の最大值 $F_{c \max }$ と, 測定誤 差である計算された丸棒先端の衝撃力 $F_{d}(T)=$ $\sigma_{d}(T) \cdot A_{2}$ の最大值 $\Delta F_{d \max }$ との比を求めた結果が図

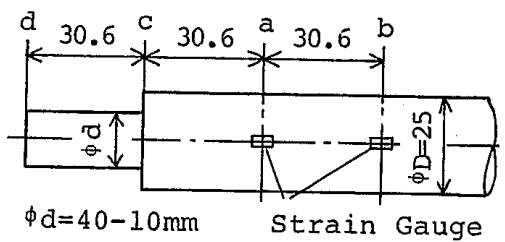

図 4 測定棒先端の形状とゲージ位置

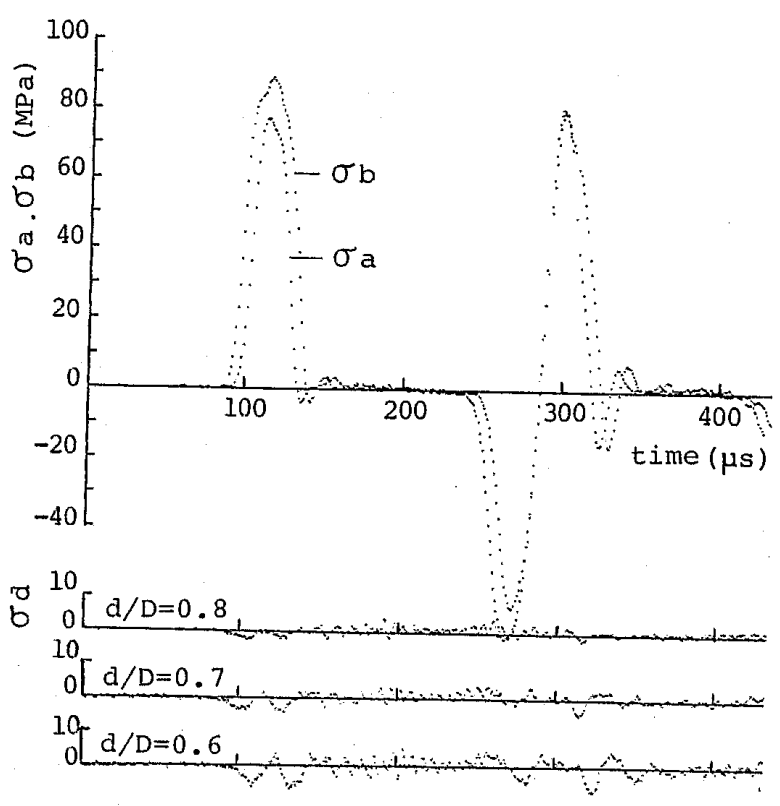

図 5 測定された $a ， b$ 点の応力と計算された丸棒先端の 応力
6 である. 図では, 直径比 $d / D$ が約 0.8 から 1.2 の範 囲では $3 \%, 0.7$ から 1.3 までの範囲では $5 \%$ 以下の 誤差となっており，段差が小さい場合には，この測定 法が十分に使用できることを示している，また，この 時の応力波の立上り時間は約 $12 \mu \mathrm{s}$ である.

また，各応力の測定点を $30.6 \mathrm{~mm}$ ずつ先端から遠 ざけて各応力を測定し, 式(18) を用いて先端の衝撃力 を計算した時の誤差は, $\mathrm{a}$ 点と $\mathrm{b}$ 点の応力から計算し た場合と比較して約 $0.5 \%$ 増加した。

このようにこの测定法が使用できることは，丸棒 の断面積がある程度急激に変化しても一次元弾性応力 波理論が十分適応できることを示している.つまり， 図 6 は，応力の立上り時間がこの実験における $12 \mu \mathrm{s}$ と同一な条件にあり，丸棒先端の加圧面から直径の 1.2 倍以上離れた位置で応力を測定する場合におい て, 直径 $D$ の丸棒で直径 $d$ の試料を高速圧縮する際 に測定データに含まれる誤差の範囲を示しているとい える。すなわち，図 6 は， $d / D=1$ の場合と比較した誤 差の量が， $d / D=0.8$ で $1 \%, d / D=0.7$ で $3 \%$ 程度で あることを示している. 深津ら ${ }^{(5)}$ は，丸棒の直径と，試 料の直径との比が変化する場合における丸棒内の応力 分布が $d / D$ が $0.4 て ゙ も ，$ 端面から直径以上離れた断 面では，応力はほぼ均一に分布する結果を示している が，本測定理論に基づいた実験においても，一次元弾 性応力波理論に基づく衝撃応力の測定においては，d/ $D$ の影響が少ないことが確かめられた。

\section{5. ま と め}

一次元弾性応力波理論に基づき, 丸棒の二点の応力 を測定して丸棒の任意の断面, 先端, 段付部および, 段付棒の先端の衝撃力を求める理論式が導かれ，その 理論の正しさと,その理論を応用したYanagihara-

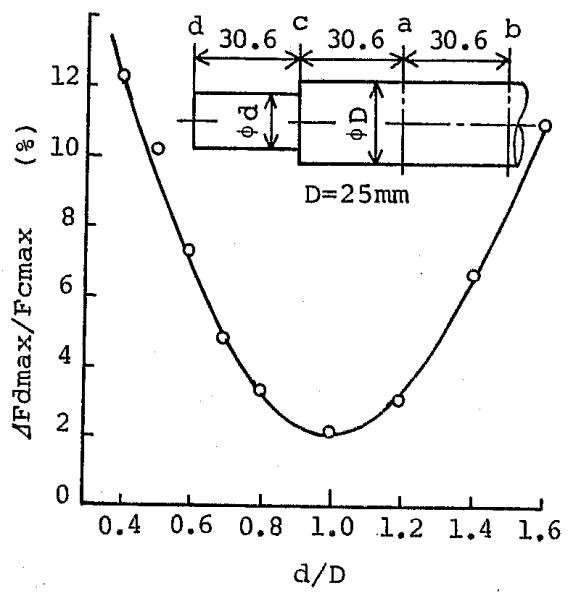

図 6 測定詔荎と段付部直径比との関係 
Bar 法による測定精度が実験によって確かめられた。 また，高速圧縮試験等に括ける加圧棒の直径と，試料 の直径との比が変化する場合の測定誤差が示された。

その主な結果を次に示す。

応力の立上り時間が $12 \mu \mathrm{s}$ 上り長い条件において

（1）直径 $D=25 \mathrm{~mm}$ の丸棒の先端が段付きとな っており,この先端に衝㢣力が加わる場合, その先端 の直径 $d$ が直径比 $d / D$ で約 0.8 から 1.2 までの範困 では $3 \%, 0.7$ から 1.3 までの範囲では $5 \%$ の以の 誤差で測定できる。

（2）材料の高速圧縮試験等に扔いて，加圧棒の直 径に対する試料の直径 $d$ の減少によって生ずる誤差
は，直径比 $d / D=1$ の場合と比較して $d / D=0.8 て ゙ 1$ $\%, d / D=0.7$ で $3 \%$ 以内である。

最後に，本研究に協力していただいた山口俊樹君 [(株)ホーチキ] 枯上び, 本学技術員の外崎猛, 安池寿 一氏に感謝の意を表す。

文献

（1）楖原，機論，43-375 (昭 52), 4048.

(2) 楖原 - 高藤, 㙨諭, 45-393 (昭 54), 601 .

（3）㧕原・斎藤, 機論, 51-464, C (昭 60), 790 .

（4）松本活加 4 名, 機論, 29-197 (昭 38)，49.

（5）深津・ほか 3 名，機論，50-453，A（昭 59)，869.

\section{討論}

〔質問〕深 津 鋼 次〔名古屋工業大学工学部〕 ホプキンソン棒法と関連して下記の点について扔た ずねしたい.

（1）異なる材質加らなる段付棒に対し貴測定法を 用いるには，反射率と透過率を考慮するのみでよいの か.

（2）段付棒の一方 (図 2 の横断面積 $A_{2}$ の部分)の 応力が降伏点を超えるときの $d$ の位置における応力 の測定が可能か.

〔回答〕（1）材質が異なる場合には, 部材の密 度 $\rho$ および縦弾性係数 $E$ が変わるため, 弾性応力波 の伝ぱ速度 $c$ および反射率 $\alpha$ と透過率 $\beta$ が違ってく る. 本測定法では，応力波が応力測定点 $\mathrm{a}-\mathrm{b}$ 間の距離 $l_{1}$ を伝ぱするのに要する時間 $t_{1}$ が基準となるため, 段付部からd点までの部材の材質が異なる場合には， その部材内の応力波の伝ぱ速度 $c_{2}=\sqrt{E_{2} / \rho_{2}}$ と, 段付 部以後の部材内の応力波の伝ば速度 $C_{1}=\sqrt{E_{1} / \rho_{1}}$ より， $k$ を整数とし, $l_{3}$ の長さを $l_{3}=k \cdot\left(c_{2} / c_{1}\right) \cdot l_{1}$ の関係が 成り立つように設定する必要がある。したがって, 式 (17)を用いてd点から段付部までの材質が異なる棒で 測定する場合には, $l_{3}=\left(c_{2} / c_{1}\right) \cdot l_{1}$ とし, $\beta_{1} \cdot \beta_{2}$ は次式 上り求める.

$$
\begin{aligned}
& \beta_{1}=\frac{2 \cdot A_{1} \cdot \rho_{2} \cdot c_{2}}{A_{1} \cdot \rho_{1} \cdot c_{1}+A_{2} \cdot \rho_{2} \cdot c_{2}} \\
& \beta_{2}=\frac{2 \cdot A_{2} \cdot \rho_{1} \cdot c_{1}}{A_{1} \cdot \rho_{1} \cdot c_{1}+A_{2} \cdot \rho_{2} \cdot c_{2}}
\end{aligned}
$$

（2）本測定理論は，応力波の伝ぱによるエネルギ の減衰を無視している.したがって，d点から段付部 までの部材が降伏応力を超えた場合には，塑性仕事に よるエネルギ隇衰が無視できなくなること，塑性変形 により $l_{3}$ の長さと断面積 $A_{2}$ が変化することによる 誤差が生じる.この誤差がどの程度となるか，また， どのように補正すればよいかなどは，今後の研究課題 であると考えている。 